\title{
Characterization of Microbial Inoculants and its Different Formulation for Mass Production
}

\author{
Geeta Kumari ${ }^{1}$, Deepak Kumar ${ }^{1}$, Devendra Singh $^{1,2 *}$ and Navnit Kumar ${ }^{3}$ \\ ${ }^{1}$ Department of Microbiology, College of Basic Sciences and Humanities, \\ Dr. Rajendra Prasad Central Agricultural University, Pusa, Samasitpur, Bihar, 848125, India \\ ${ }^{2}$ ICAR-Directorate of Medicinal and Aromatic Plants Research, \\ Boriavi, Anand, Gujarat-387310, India \\ ${ }^{3}$ Department of Agronomy, Sugarcane Research Institute, Dr. Rajendra Prasad Central \\ Agricultural University, Pusa, Samasitpur, Bihar, 848125, India \\ *Corresponding author
}

\section{A B S T R A C T}

\begin{tabular}{|l|}
\hline Ke y w o r d s \\
Carrier materials, \\
Additives, \\
Microbial \\
inoculants, Growth \\
pattern, IAA \\
production
\end{tabular}

\begin{abstract}
Biofertilizers are alternative source of nutrient inputs in sustainable agriculture. Plant growth promoting microorganisms such as Rhizobium spp. and Bacillus spp. can be used as biofertilizers. In our present study, different Rhizobium and Bacillus isolates were screened for the selection of suitable medium for its maximum growth at different incubation period. The Growth pattern of Rhizobium isolates were evaluated in two different media viz. Nutrient broth and YEM broth while of Bacillus spp. on four different media viz. LGD broth, Nutrient broth, NYSM broth and BMS broth. Our results revealed that the YEM broth supported better growth of Rhizobium isolates than Nutrient broth. However, the maximum growth of Bacillusspp. was observed in BMS broth while least in LGD broth at O.D ${ }_{620 \mathrm{~nm}}$ after $72 \mathrm{hrs}$.But there was the problem to take optical density because of formation of black pellicle in BMS media byBacillus spp. Therefore, we conclude that NYSM media is best media for the growth of Bacillus spp. Rhizobium and Bacillus spp. were evaluated for IAA production. Bacillus spp. was found more efficient than Rhizobium in terms of IAA production. For different carrier materials like Charcoal, Fly-ash and additives such as Glycerol and Trehalose were used over a period of 15 days of storage to assess the survivability of different Rhizobium and Bacillus isolates. Based on the finding of the study, the charcoal can be used as an alternate carrier material to prepare the microbial inoculants. However, the liquid inoculants were found to be better in supporting the population of inoculants than the carrier based inoculants.
\end{abstract}

\section{Introduction}

Biofertilizers assume a significant agent for enhancing the fundamental plant nutrients for sustainable agriculture because these are economically feasible and eco-friendly. The biofertilizers are preparation of living cells or latent cells of efficient strains of microorganisms which enhance the uptake of nutrients by plants by interaction in rhizosphere soil (Motsara et al., 1995). Rhizobium is a significant symbiont for legumes however it can be useful for nonlegume plants by delivering phytohormones. Phytohormone enhances the plant growth, lateral root formation, root 
development, stem elongation and signal transformation. Bacillus spp. advanced plant development by various mechanisms, likePhosphorus solubilization, Zinc solubilization, K solubilization, micronutrients uptake and translocation, suppressing of phytopathogens and secretion of phytohormones, for example, Indole Acetic Acid (Choudhary and Johri, 2009; Gutiérrez et al., 2003).

Carrier based biofertilizers are more prevalent in India, in general, it is suffer from short shelf life, poor quality, high contamination and unpredictable field performance. Death of the organisms in the inoculated seed is one of the important factors contributing the failure of inoculation response in field condition. Much research is done in India on Rhizobium strain selection and formulation technologies are limited.

A break through is needed in the inoculants technology to improve the shelf life and field efficacy of bio-fertilizers in India to make them commercially viable and acceptable to farmers. One of the main problem in inoculants technology is the survival of micro-organisms during storage and several parameters such as culture medium, physiological state of the microorganisms when harvested (Alexander, 1977) the process of dehydrates, rate of drying the temperature storage and water activity (Aw) of the inoculums have an influence on their shelf life.

So, studies to increase the shelf life of inoculants or finding alternate formations for carrier based inoculants are important. Moisture retaining capacity of the $\mathrm{CBBF}$ is very low which does not allow the organism viable for longer period and the $\mathrm{LBF}$ facilitates the enhanced viability of the organism (Mahdi et al., 2010). In the present study experiments have been conducted to improve the shelf life and quality parameters of microbial inoculants of Rhizobium isolatesand bacillus spp.by the addition of suitable additives and also developing new formulation such as liquid inoculants. Therefore, present investigation was undertaken to Characterize Rhizobium and Bacillus inoculants morphologically and biochemically and assess the survival of microbial Inoculantsin different carrier materials and liquid formulations.

\section{Materials and Methods}

\section{Origin of isolates}

Three isolates of Rhizobium were taken from different soil type of Bihar that is, from Tal land and Bacillus isolate was taken from Maize rhizophere of diara soil. These isolates were selected to characterize and used to formulate liquid biofertilizer by the use of moisture protectants. All these isolates were obtained from Department of Microbiology in Faculty of Basic Sciences \& Humanities, Rajendra Agricultural University, Pusa, Samastipur, Bihar.

Three promising Rhizobium strains and Bacillus isolate were selected for further morphological and colony characteristics. Growths of different isolates were measured by taking optical density after incubation of different time interval at $35 \pm 2^{\circ} \mathrm{C}$. The Growth pattern and selection of suitable medium for optimum growth of different Rhizobium isolates were evaluated in two different media viz. Nutrient broth and Yeast extract mannitol broth while of Bacillus spp. on four different media. viz. LGD broth, Nutrient broth, NYSM and BMS broth by measuring O.D at $620 \mathrm{~nm}$ after incubating them for 24 hours, 48 hours and 72 hours at $35 \pm 2{ }^{\circ} \mathrm{C}$. These isolates were further studied for growth parameters, Indole Acetic Acid (IAA) production which acts as growth promoter. 


\section{Collection and analysis of carrier materials}

Rhizobium and Bacillus isolates were obtained from Microbiology Department of Faculty The carrier materials like, flyash and charcoal were collected from department of soil science, Dholi and were used in the present study. All the carrier materials were dried in shade, powdered through 60 micron sieve. These materials were analysed for their physical and chemical characters viz., water holding capacity (Emmanuel et al., 2010), bulk density (Emmanuel et al., 2010), pH (Piper, 1966), organic carbon content (Walkley and Black, 1934) and electrical conductivity (Piper, 1966).

\section{Preparation of carrier based formulations of different rhizobium isolates and bacillus spp.}

These formulations were developed as described by Vidhyasekaran and Muthamilan, (1995) by using a mixture of $30 \mathrm{ml}$ of different microbial inoculants with $100 \mathrm{~g}$ of carrier. The carriers were autoclaved for 1 hour on each of two consecutive days. Rhizobium and Bacillus strain were grown on YEM broth and BMS broth for $48 \mathrm{~h}$ as a shake culture in rotary shaker at $150 \mathrm{rpm}$. at room temperature $\left(25 \pm 2^{\circ} \mathrm{C}\right) \quad$ containing $9 \times 108$ colony forming units (CFU) per $\mathrm{ml}$ was added to $100 \mathrm{~g}$ of the carrier material i.e charcoal and flyash and mixed well under sterile conditions. Then packed in polythene bags, sealed and stored at room temperature (25 \pm 2 ÚC) and with a moisture content of $35 \%$, In each carrier, the population of bacteria was estimated by using serial dilution technique.

\section{Preparation of liquid inoculants}

The YEM broth inoculated with different Rhizobium isolates in $250 \mathrm{ml}$ conical flask. It was allowed to multiply by incubating at
$30 \pm 2^{0} \mathrm{C}$ in a incubator cum shaker at $100 \mathrm{rpm}$ for 72 hours. The broth containing approximately $25 \times 10^{11} \mathrm{CFU} / \mathrm{ml}$ was used as a starter culture for the production of liquid bioinoculant. The broth was mixed with sticking and spreading agents viz., Glycerol and Trehalose were added at the rate of $2 \mathrm{ml}$, / $100 \mathrm{ml}$. They were packed in $100 \mathrm{ml}$ lot in opaque low density grade polypropylene bags of thickness 75 micron as per the procedure followed by Somasegaran. The liquid inoculants of Rhizobium isolates and Bacillus spp. were analyzed initially for their survival. The estimation of population was done by serial dilution and plating method.

\section{Results and Discussion}

\section{Source of isolates}

Rhizobia are known to supply biologically fixed nitrogen directly to the legume plant and also have great relevance in improving pulse productivity. Accordingly in the present study, three different Rhizobium spp. were selected from Chickpea, lentil and gram nodule of Tal land of Bihar and Bacillus spp. were selected form Maize rhizosphere of Diara soil of Bihar.

Growth of different Rhizobium spp. and Bacillus spp.in different media

Different Rhizobium isolates having origin from different soils were screened for the selection of suitable medium for its maximum growth. Growth pattern of different Rhizobium isolates were measured at $\mathrm{OD}_{620}$ after incubation of $24 \mathrm{hrs}, 48 \mathrm{hrs}$ and $72 \mathrm{hrs}$ at $35 \pm 2^{\circ} \mathrm{C}$. The optical density of Rhizobium isolates were obtained on Nutrient broth and YEM broth. The perusal of data in (Table 1) reveals that maximum growth of Chickpea, Lentil and Pea isolates were observed as 1.770, 2.047 and 0.875 respectively in YEM broth and 1.495, 1.268 and 0.612 in Nutrient 
media broth at the end point of 72 hours. It indicates that YEM broth supports better growth of isolates than Nutrient media broth for different Rhizobium isolates. The growth was increasing with time of incubation and at the endpoint of 72 hours the growth was highest.

Similarly, the Bacillus spp. was evaluated for growth potential in four different Growth media viz. LGD broth, Nutrient broth, NYSM broth and BMS broth. Growth pattern of Bacillus spp. were measured in four different different media viz. LGD broth, Nutrient broth, NYSM broth and BMS broth at $\mathrm{OD}_{620 \mathrm{~nm}}$ after incubation of $24 \mathrm{hrs}, 48 \mathrm{hrs}$ and $72 \mathrm{hrs}$ at $35 \pm 2^{\circ} \mathrm{C}$. The data suggested maximum growth was observed in BMS broth i.e 1.321 while least growth in LGD broth i.e 0.899 at O.D 620nm, after $72 \mathrm{hrs}$ (Table 2 ). But there was the problem to take optical density because of formation of black pellicle in BMS media by Bacillus spp. The growth was increasing with time of incubation and at the endpoint of 72 hours the growth was highest.

\section{Morphological characterization}

Colony morphology of different Rhizobium and Bacillus isolates were also examined in different media. Both isolates were studied for morphological and Culture characteristics which comprised of the appearance, pigmentation, shape, size, margin, and elevation, of the colonies on standard Medium that is, YEMA for Rhizobium isolates and NYSM for Bacillus sp.(Table 3). In case of Bacillus spp., the Morphology and Colony Characteristics on the standard medium was round shape, entire margin, drop like elevation, wet gummy colony appearance and slightly whitish pigmentation. In case of Mesorhizobium and Rhizobium leguminosarum spp., the morphology and Colony Characteristics on the standard medium was circular shape, entire margin, convex elevation, wet gummy colony appearance and white pigmentation .

\section{IAA production}

Numerical strength of microorganism plays an important role in sustaining the soil health and plant growth. Bihar soil is rich in Mesorhizobium, Rhizobium leguminosarum and Bacillus spp. populations. The role of Rhizobium sps. as a PGPR was also evaluated and isolates exhibit IAA production with values ranging from 0.294 to $0.964 \mu \mathrm{g} / \mathrm{ml}$ in (Table 4). This suggests that Mesorhizobium was poor in IAA production. The role of Bacillus spp. as a PGPR was also evaluated and isolates exhibit IAA production with values of $20.04 \mu \mathrm{g} / \mathrm{ml}$. This suggests that Bacillus spp. was excellent in IAA production. Role of different Rhizobium and Bacillus isolates as plant growth promoter has been documented (Bhasan et al., 2004).

\section{Physico-chemical properties of carrier materials}

The physico-chemical properties such as organic matters, $\mathrm{pH}, \mathrm{EC}$, Bulk density, and water holding capacity were estimated for the carrier materials like Charcoal and Flyash (Table 5).The organic matter content was maximum in Charcoal $(5.30 \%)$. Flyash recorded minimum organic matter content of $(0.36 \%)$. The $\mathrm{pH}$ of charcoal was 7.1 followed fly ash 6.4. The Low electrical conductivity value was recorded in charcoal $(0.49 \mathrm{dS} / \mathrm{m})$ than fly ash $(0.65 \mathrm{ds} / \mathrm{m})$.The Bulk density of $0.75 \mathrm{~g} / \mathrm{cm}^{3}$ and $0.47 \mathrm{~g} / \mathrm{cm}^{3}$ was recorded in Charcoal and flyash. The flyash was observed to show the maximum water holding capacity (63.0\%), whereas Charcoal recorded $(52.6 \%)$. The physico-chemical characters of carrier materials have got profound influence on the survival of inoculants. 
Table.1 Growth of different Rhizobium sps.in different media composition at different time interval

\begin{tabular}{|c|c|c|c|c|c|c|c|}
\hline \multirow[t]{2}{*}{ S.NO } & \multirow[t]{2}{*}{ Isolates } & \multicolumn{2}{|c|}{ O.D ${ }_{620}(24 h r)$} & \multicolumn{2}{|c|}{ O.D ${ }_{620}(48 \mathrm{hr})$} & \multicolumn{2}{|c|}{ O.D $\mathrm{D}_{620}(72 \mathrm{hr})$} \\
\hline & & N.M & YEM & N.M & YEM & N.M & YEM \\
\hline 1 & Chickpea & 0.921 & 1.509 & 1.328 & 1.658 & 1.495 & 1.770 \\
\hline 2 & Lentil & 0.684 & 1.456 & 0.866 & 1.553 & 1.268 & 2.047 \\
\hline 3 & Pea & 0.141 & 0.251 & 0.453 & 0.616 & 0.612 & 0.875 \\
\hline
\end{tabular}

Table.2 Growth of Bacillus spp. in different media composition at different time interval

\begin{tabular}{|c|c|c|c|}
\hline Media & O.D $_{\text {620 }}(\mathbf{2 4 h})$ & O.D $_{\text {620 }}(\mathbf{4 8 h})$ & O.D $_{\text {620 }}(\mathbf{7 2 h} \mathbf{)})$ \\
\hline BMS & 0.430 & 0.721 & 1.321 \\
\hline LGD & 0.123 & 0.460 & 0.899 \\
\hline NYSM & 0.301 & 0.612 & 1.012 \\
\hline NM & 0.212 & 0.472 & 0.952 \\
\hline
\end{tabular}

Table.3 Morphology and Colony Characteization of different isolates

\begin{tabular}{|c|l|c|c|c|c|c|c|}
\hline $\begin{array}{l}\text { S. } \\
\text { No }\end{array}$ & Isolates & Shape & Margin & Elevation & $\begin{array}{c}\text { Colony } \\
\text { appearance }\end{array}$ & Size & Pigmeatation \\
\hline $\mathbf{1}$ & Bacillus spp. & round & entire & drop like & wet gummy & tiny & slightly whitish \\
\hline $\mathbf{2}$ & $\begin{array}{l}\text { Rhizobium } \\
\text { (Chickpea) }\end{array}$ & circular & entire & convex & wet gummy & small & White \\
\hline $\mathbf{3}$ & $\begin{array}{l}\text { Rhizobium } \\
\text { (Lentil) }\end{array}$ & round & entire & convex & moist wet & small & slightly whitish \\
\hline $\mathbf{4}$ & $\begin{array}{l}\text { Rhizobium } \\
\text { (Pea) }\end{array}$ & round & entire & convex & moist wet & tiny & slightly whitish \\
\hline
\end{tabular}

Table.4 IAA production of different Isolates

\begin{tabular}{|c|c|l|}
\hline S.No. & Isolates & IAA Production \\
\hline $\mathbf{1}$ & Bacillus species & 20.04 \\
\hline $\mathbf{2}$ & Rhizobium (Chickpea) & 0.967 \\
\hline $\mathbf{3}$ & Rhizobium (Lentil) & 0.294 \\
\hline $\mathbf{4}$ & Rhizobium (Pea) & 0.456 \\
\hline
\end{tabular}

Table.5 Physico-chemical properties of charcoal and fly-ash carrier material

\begin{tabular}{|l|l|c|c|c|c|c|}
\hline S.No & Carrier & $\mathbf{p H}$ & $\begin{array}{c}\text { organic } \\
\text { matter content } \\
(\mathbf{\%})\end{array}$ & $\begin{array}{c}\mathbf{E C} \\
\mathbf{( d s / m )}\end{array}$ & $\begin{array}{c}\text { Bulk } \\
\text { density } \\
\left(\mathbf{g} / \mathbf{c m}^{\mathbf{3}}\right)\end{array}$ & $\begin{array}{c}\text { Water holding } \\
\text { capacity } \\
(\mathbf{\%})\end{array}$ \\
\hline $\mathbf{1}$ & Charcoal & 7.1 & 5.30 & 0.49 & 0.75 & 52.6 \\
\hline $\mathbf{2}$ & Flyash & 6.4 & 0.36 & 0.65 & 0.47 & 63.0 \\
\hline
\end{tabular}


Table.6 Population of different isolates in different formulation

\begin{tabular}{|l|c|c|c|c|}
\hline \multirow{2}{*}{ Formulation } & Bacillus spp. & \multicolumn{1}{|c|}{$\begin{array}{c}\text { Rhizobium } \\
\text { (Chickpea) }\end{array}$} & $\begin{array}{c}\text { Rhizobium } \\
\text { (Lentil) }\end{array}$ & $\begin{array}{c}\text { Rhizobium } \\
\text { (Pea) }\end{array}$ \\
\hline Charcoal & \multicolumn{3}{|c|}{$\mathbf{x ~ 1 0}$} \\
\hline Flyash & 5.0 & 10.2 & 12.0 & 8.5 \\
\hline Liquid & 4.5 & 9.0 & 10.2 & 8.0 \\
\hline
\end{tabular}
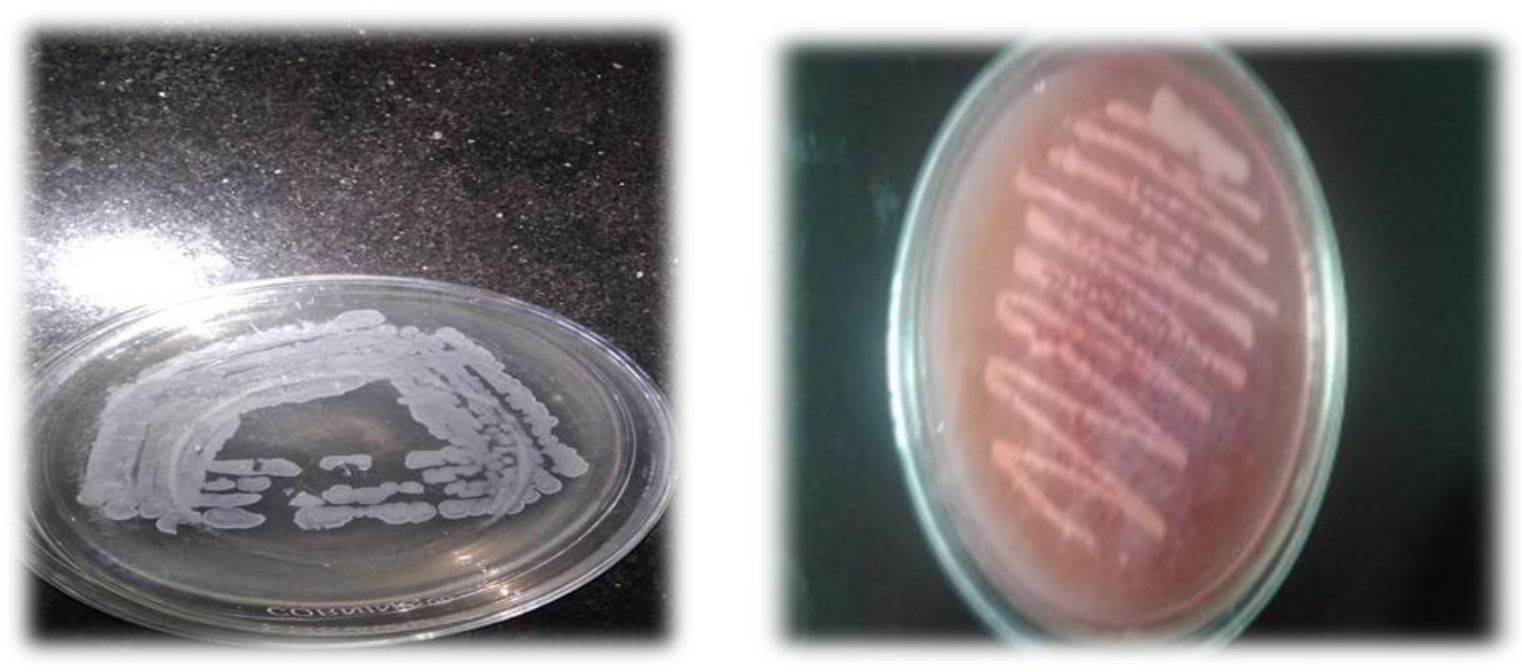

Plate.1 Pigmentation and colony morphology of Rhizobium and Bacillus spp

The ideal characteristics of an inoculant carrier include more surface area, rich in organic matter, high water holding capacity, neutral $\mathrm{pH}$, easy availability and inexpensiveness.

The Population of different isolates in different formulations viz., charcoal, flyash and liquid were estimated under sterile condition over a period of 15 days at room temperature.

The result is presented in (Table 6). The population of different Rhizobium and Bacillus isolates over a 15 days of storage reveals that liquid inoculants supported maximum population in Pea isolates i.e $\left(18.2 \times 10^{9}\right)$ followed by Lentil $\left(17.0 \times 10^{9}\right)$, Chickpea $\left(15.6 \times 10^{9}\right)$ and Bacillus spp. (12.3 x $10^{9}$ ).
Among the different formulations tested the liquid inoculants supported the maximum population of 15 days of storage followed by charcoal and Flyash.

Based on the finding of the study, we conclude that YEM broth supported better growth of Rhizobium isolates while, NYSM media is best media for the growth of Bacillus spp. The charcoal can be used as an alternate carrier material to prepare the microbial inoculants, whereas, the liquid inoculants were found to be better in supporting the population of inoculants than the carrier based inoculants.

Hence, It has been recorded that the liquid formulation supported the maximum population compared to other formulation. However, further studies are needed for Screening different concentration of 
additives to standardize liquid formulation and to enhance the shelf-life of microbial inoculants -viz- validation of its efficiency under field conditions.

\section{References}

Alexander M. (1977) Introduction to soil microbiology $2^{\text {nd }}$ Edn., John Wiley and Sons Inc., New York and London, 461.

Bashan Y, de Bashan LE. (2005). Bacterial plant growth promotion. In: Hillel D, editor. Encyclopedia of soils in the environment. Oxford: Elsevier; pp. 103-115.

Choudhary, D. K. and B. N. Johri (2009). Interactions of Bacillus spp. and plantsWith special reference to induced systemic resistance (ISR). Microbiol. Res. 164: 493-513.

Emmanuel, D. A., Verhoef, A., Robinson, S. and Sohi, S. B. (2010). Bio-char from sawdust, maize stover and charcoal: Impact on waterholding capacities (WHC) of three soils from Ghana. 19th World Congress of soil science, soil solutions for a changing world 1-6 August 2010, Brisbane, Australia.

Gutierrez Mañero, F. J., A. Probanza, B. Ramos, J. J. Colón Flores and J. A.
Lucas García (2003).Ecology, Genetic Diversity and Screening Strategies of Plant Growth Promoting Rhizobacteria (PGPR). J. Plant Nutr., 26 (Suppl 5): 1101-1115.

Kloepper, J. W. and C. J. Beauchamp (1992). A review of issues related to measuring colonization of plant roots by bacteria. Can. J. Microbiol, 38:1219- 1232.

Mahdi SS, Hassan GI, Samoon SA, Rather HA, Dar SA, et al., (2010).Biofertilizers in Organic Agriculture. $\mathrm{J}$ Phytol 2: 42-54.

Motsara MR, Bhattacharyya P.Srivastava B. (1995). Biofertilizers Technology, Marketting andUsage -A Sourcebook cum - glossary.Fertiliser Development and Consultation Organisation. New Delhi, India, 37-39.

Piper, G. S. (1966).Soil and plant analysisInterscience Pub. Inc., New York.

Vidhyasekaran, P. and Muthamilan, M. (1995). Development of formulations of Pseudomonas fluorescens for control of chickpea wilt. Pl. Dis. 79: 782-786.

Walkley, A. and Black, I. A. (1934). An examination of the degtjareff method for determining organic carbon in soils: Effect of variations in digestion conditions and of inorganic soil constituents. Soil Sci. 63: 251-263.

\section{How to cite this article:}

Geeta Kumari, Deepak Kumar, Devendra Singh and Navnit Kumar. 2020. Characterization of Microbial Inoculants and its Different Formulation For Mass Production. Int.J.Curr.Microbiol.App.Sci. 9(07): 621-627. doi: https://doi.org/10.20546/ijcmas.2020.907.070 